\title{
EL PBI \\ ¿UN INDICADOR ANACRÓNICO?
}

José Domingo Begazo (")

E-mail:d180045@mixmail.com

Ricardo Torres Agurto (**)

E-mail:agurtord@yahoo.es

\section{RESUMEN}

Cuando una futura generación estudie nuestra civilización y vea que contabilizamos como desarrollo un crecimiento económico que consistía en destruir la biodiversidad, recalentar la atmósfera, derretir los glaciares, crear escasez de agua, alimentos y energía, y subir peligrosamente el nivel de los mares propiciando el "oscurecimiento global", con seguridad que clasificarían al Producto Bruto Interno (PBI) como el más conspicuo indicador de nuestra barbarie.

Palabras clave: PBI, Oscurecimiento Global, Cambio Climático, Bienestar Social, Recursos Naturales.

\section{ABSTRACT}

When a future generation see study our civilization and development which are recognized as economic growth which was to destroy biodiversity, warm the atmosphere, melting glaciers, creating shortages of food, water and energy and dangerously raise sea levels, resulting in "global dimming" classify the gross domestic product (PBI) as the most conspicuous indicator of our barbarity.

Key words: PBI, Global Dimming, Climate Change, Social Welfare, Natural Resources.

(*) Doctor y Magíster en Administración. Magister en Desarrollo Económico Social. Profesor Principal y Miembro Permanente de la Unidad de Investigaciones de la FFCCAA de la UNMSM. Reconocimiento al Mérito Científico UNMSM en los años 2001, 2002 y 2003. Conferencista Internacional. Autor de artículos y libros sobre su especialidad.

(**) Egresado de la Maestría en Administración. Sociólogo. Profesor universitario y Jefe de la Oficina de Planificación, Proyectos y Presupuestos de la FFCCAA de la UNMSM. 


\section{INTRODUCCIÓN}

Fue en la década del 90 cuando Alvin Toffler vino por primera vez a Lima, y una de sus expresiones mas contundentes fue que los economistas debían de tirar al tacho todos sus libros sobre Economía. Su explicación era que dichos libros solamente enseñaban modelos de visión de una sociedad industrial ya caduca y que se estaba entrando a un nuevo tipo de sociedad llamada cognomática.

Agregó que en muchos libros y aulas de Economía se seguía enseñando que los factores de producción (según Samuelson) eran tierra, capital y trabajo, y que su contabilidad está asociada a la aparición del capitalismo, la acumulación de capital y la posibilidad de adquirir más activos.

Con la consolidación de los Estados, se diseñó un sistema para medir la actividad económica de un país que exigía saber cuánto se ganaba, cuál era la diferencia entre el gasto de producción y los ingresos por venta, solo por dar algunos ejemplos.

El surgimiento y la consolidación del capitalismo y de la Economía de Mercado están asociados también a la utilización intensiva de los recursos naturales y al deterioro del ambiente ${ }^{1}$.

La Liga de las Naciones publicaba estadísticas de sus miembros, y actualmente el Banco Mundial clasifica a los países de acuerdo con sus niveles de PBI per cápita que da lugar a "tipos" de países: elegibles o no elegibles para tipos de ayuda.

\section{DEFINIENDO EL PBI}

El PBI es uno de los indicadores más importantes de nuestra economía. Todos los gobiernos tratan de medir la efectividad de su gestión con indicadores que demuestren que el PBI nacional está creciendo.

- Definición 1. Es el valor monetario del conjunto de bienes y servicios finales producidos en un período de tiempo determinado y en un territorio económico determinado.
- Definición 2. Es el indicador que mide la actividad económica de un país, es el ratio que calcula a cuánto asciende la producción total de un país.

- Definición 3. Se define como el valor total de los bienes y servicios generados en el territorio económico durante un período de tiempo, que generalmente es un año, libre de duplicaciones.

El PBI también se puede definir como el valor añadido en el proceso de producción y mide la retribución a los factores de producción que intervienen en el proceso de producción.

Para cuantificar el Producto Bruto Interno existen tres métodos: producción, gasto e ingreso. El circuito económico se puede resumir de la siguiente manera:

- Producción: ¿Qué se produce?: bienes y servicios.

- Gasto: ¿Cómo se utiliza?: en consumo, inversión y exportaciones.

- Ingreso: ¿Cómo se reparte?: en remuneraciones, impuestos a la producción e importaciones netos de subsidios, consumo de capital fijo y excedente neto de explotación.

Se suele interpretar al PBI según su evolución; es decir, si es ascendente durante un período de tiempo, la economía estará "creciendo"; si es descendente estará en "recesión".

El PBI es usado frecuentemente como una medida del bienestar material de una sociedad, eso motiva que se usen las cifras del crecimiento económico del PBI como un indicador de que las políticas económicas aplicadas son positivas.

\section{CRÍTICAS A ESTE INDICADOR}

El Premio Nóbel de Economía, Joseph Stiglitz, explica que utilizando la metodología tradicional de las cuentas nacionales se puede incurrir en paradojas tales como un crecimiento sostenido del indicador PBI durante varios años, acompañado

1 Para precisar este término adjuntamos un resumen de Aroca Sanz, Juan. (2008), donde explica cuál debería ser el término correcto: medio ambiente, medio o ambiente. La ecología se ocupa del ser vivo... y de su ambiente, medio o hábitat, vocablo con el que a veces nos obsequian. Si dijéramos que se ocupa del ser vivo y de su medio ambiente, estaríamos cometiendo un pecado de redundancia. Medio, como nombre, tiene una acepción que dice: "elemento en que vive o se mueve una persona, animal o cosa" y ambiente, como adjetivo, "se aplica a cualquier fluido que rodea los cuerpos" y también, "circunstancias que rodean a las personas o cosas". Decir, pues, medio ambiental o medio ambiente es pecar de demasía, o de redundancia. Esta es la razón por la cual el Ministerio creado por el actual gobierno es el Ministerio del Ambiente. 
de elevados índices de pobreza. Ello se debe a que el PBI no mide adecuadamente los cambios que afectan al bienestar, ni permite comparar correctamente el bienestar de diferentes países; sólo compensa a los gobiernos que aumentan la producción material.

El PBI mide tan solo lo material, no es un indicador de "calidad de vida" o "bienestar", razón por la cual se ha criticado su uso como sinónimo de bienestar social. J. E. Stiglitz y Amartya Sen exhortan a la adopción de nuevas herramientas de evaluación que incorporen una preocupación más amplia por el bienestar humano que sólo el crecimiento económico.

De acuerdo con sus cálculos, gran parte del desastre económico contemporáneo se debe a la suposición mal concebida de que los elaboradores de políticas simplemente tenían que enfocarse en fomentar el crecimiento, confiando en que este maximizaría la prosperidad de todos.

Según indican, gran parte del mundo ha sido gobernado desde hace mucho por una fijación enfermiza por elevar el PBI, así como la cantidad de bienes y servicios que produce la economía. Stiglitz señala:

“...vemos al PBI como una medición de qué tan bien nos está yendo, y eso no nos dice si es sustentable... y lo que empezó como una medición del desempeño del mercado se ha vuelto cada vez más una medición del desempeño social y eso está mal".

No toma en cuenta la degradación del ambiente ni la desaparición de los recursos naturales a la hora de cuantificar el crecimiento, tampoco descuenta la depredación de los recursos naturales no renovables y la emisión de gases de efecto invernadero; es decir, acepta un crecimiento económico que usa al ambiente como si fuera una materia prima inagotable.

A pesar de que el crecimiento del PBI significa destrucción del hábitat humano, la mayoría de economistas, y sobre todo los políticos, rinden culto a este crecimiento como el summun del desarrollo de la riqueza nacional.

¿Cómo recoge el PBI el deterioro de los recursos naturales y del ambiente? La pérdida de la capacidad productiva, causada por la erosión de suelos no se contabiliza por sí misma sino cuando se constatan reducidos ingresos por la explotación del suelo degradado.

Según los marginalistas, el valor proviene del deseo de pagar de los consumidores. El concepto clave es la creación de valor y, el momento en que éste se crea o se agrega. Para determinar el valor no importa si su producción involucra el trabajo; lo importante es el deseo de pagar del consumidor. Si ningún consumidor deseara pagar suma alguna por dicho bien, el bien no valdría nada. Subyace a esta noción, una transacción, es decir, un mercado. Por ejemplo: la silla que compramos para nuestra casa. Si el árbol proviniera de la Amazonía, las actividades para producirla serían:

- Identificar el árbol para el corte.

- Cortarlo.

- Transportarlo hasta un aserradero.

- Aserrarlo.

- Transportar la madera aserrada hasta una carpintería.

- Diseñar la silla.

- Fabricar la silla de acuerdo con el diseño.

- Transportar la silla fabricada hasta el comercializador.

- Exhibirla para venta.

- Venderla.

El simple hecho de que el árbol exista no es fuente directa de ningún valor.

La acción de la lluvia, de los nutrientes y del resto de plantas que contribuyeron al crecimiento del árbol cortado no le agrega valor en tanto no constituyen acciones humanas.

La teoría económica y la contabilidad nacional son antropocéntricas ${ }^{2}$, se utilizan para medir los resultados de la actividad económica realizada por seres humanos, y los recursos naturales y el ambiente se contabilizan en tanto agreguen valor, y al ser intercambiados en el mercado son acciones antropogénicas ${ }^{3}$.

Para los recursos naturales:

- Su valor se contabiliza mientras sean dispuestos para los consumidores, lo que se agregará al PBI o al Producto Nacional Bruto (PNB).

2 Antropocéntrico: concepción que supone que el hombre es el centro de todas las cosas y el fin absoluto de la naturaleza.

3 Antropogénico: Acción o efecto producido directa o indirectamente por las actividades humanas. 
- Ese valor no es un valor intrínseco del recurso, sino los pagos para que sea útil.

- El agotamiento que no genera cargo por depreciación no se toma en cuenta.

Un activo natural puede agotarse y ser eliminado como fuente de ingresos lo que no se registra; solo será agregado lo que es sujeto de una transacción cuando tiene mercado. No son regalos de la naturaleza: al extraerlos quedan menos disponibles para el futuro.

Los bienes ambientales se definen porque no pueden ser transados, para los cuales no existe un mercado establecido. Los recursos naturales y el ambiente son parte del acervo de capital de la sociedad, y su consumo sin reposición significa empobrecimiento.

Tenemos que entender que el territorio no es sólo una mercancía o una propiedad; algunas veces puede llegar a ser la conjunción de diferentes capas de existencia en donde la convivencia armoniosa es posible, agregando a esto la visión indígena amazónica de territorio.

Stiglitz también resaltó que, además de la exclusión del valor de los recursos naturales, el PBI tiene otras limitaciones como indicador fiable del crecimiento económico, y que es recomendable trabajar a la par con otros indicadores tales como el PNB, que contabiliza sólo la parte del producto generada por empresas nacionales, con el fin de contabilizar con precisión cuál es la magnitud del denominado "chorreo económico", pero no tiene en cuenta los recursos naturales o mineros del país, de allí la imperiosa necesidad que los países con abundantes recursos naturales (como es el caso del Perú) incorporen a la contabilidad nacional el valor de dichos activos, mediante las técnicas popularmente conocidas como "Contabilidad Verde".

Esto lo podemos apreciar cuando se decide dar en concesión un campo minero, otorgando ventajas tributarias (cero royalties). En ese escenario, si bien el PBI nacional se eleva merced a la mayor producción de minerales, el grueso de la población no percibe el crecimiento económico puesto que la mayor parte de los ingresos emigran del país hacia la casa matriz de la empresa minera. En este ejemplo, lo que la "Contabilidad Verde" indica es que el balance de la riqueza del país habría disminuido, ya que contaría con menos activos al reducirse las reservas mineras.

\section{NUEVOS INDICADORES MÁS AJUSTADOS A LA REALIDAD}

Hoy se están haciendo esfuerzos para reemplazar el PBI con nuevos indicadores más científicos y éticos, y se han propuesto medidas relacionadas con el PBI que contabilicen las externalidades ${ }^{4}$ negativas y el efecto de la actividad económica sobre el ambiente, para tener una medida más inclusiva y más directamente relacionada con el bienestar social, como por ejemplo:

- El Índice del Bienestar Económico Sostenible (IBES), creado por los profesores Herman E. Daly y John B. Cobb Jr. de la Universidad de Maryland. Este nuevo cálculo de la prosperidad sustrae del PBI las pérdidas ecológicas. Cuando lo aplicaron, la prosperidad de los Estados

4 ¿Qué son las externalidades? Tenemos varias definiciones: costos o beneficios de una transacción económica que recaen sobre agentes que no participan en la transacción, como resultado de la falta de derechos de propiedad. Según K. Arrow: "La externalidad es el caso clásico de mercado incompleto para un activo ambiental". Una externalidad existe cuando las decisiones de producción o consumo de un individuo o firma afectan el bienestar de otros individuos o firmas, y se violan las condiciones para una asignación eficiente de recursos.

Para que los mercados funcionen eficientemente deben existir dos condiciones: que no hayan diferencias entre el costo privado y el costo social, y que todos los bienes y servicios intercambiados en los mercados sean privados y no públicos. Cuando hablamos de costos privados nos referimos a los costos incurridos por el individuo o empresa que lleva a cabo una actividad económica en particular; los costos sociales son los costos incurridos por toda la sociedad como resultado de esa actividad económica. Cuando existen diferencias entre los costos privados y los costos sociales se crean efectos externos o externalidades, los cuales son asumidos por el resto de la sociedad, sin que medie algún tipo de compensación.

Cuestiones económicas de las externalidades: al ser los servicios ambientales de libre acceso y disfrute, se generan distorsiones y fallas en los mercado, como la liberación de gases o partículas en cantidades superiores a la capacidad de dispersión de una cuenca atmosférica, lo que puede generar la aparición de externalidades negativas en sectores como el turismo, la agricultura, la salud, los seguros, etc., encareciendo indebidamente sus costos operativos y consecuentemente sus precios finales (distorsiones).

Cuestiones ambientales de las externalidades: la economía ambiental, busca evitar la aparición de externalidades y distorsiones en los mercados a través de diversos instrumentos. El Estado puede intervenir mediante diversos mecanismos que permitan regularizar un comportamiento sobre algo que carece de derechos de propiedad, mediante: cargos por emisiones (Protocolo de Kyoto), permisos negociables (análisis de costo-beneficio), e impuestos. 
Unidos cambió ya que su renta per cápita venía declinando en 10\% desde 1976.

- El Indicador de Progreso Genuino (GPI), que también sustrae del PBI los costos externos de la destrucción de recursos no renovables, a los que añade la contaminación, el desperdicio de energía, la congestión del tráfico y los costos de la delincuencia. Tras aplicarlo, la renta per cápita de Estados Unidos entre 1982 y 2002 no creció $56 \%$, como oficialmente se calculó, sino tan solo $2 \%$.

- La Factoría Inversa, propuesta del profesor Horoyuki Yoshikawa de la Universidad de Tokio, quien dice que se debe establecer en el mundo un nuevo sistema cíclico industrial, compuesto por industrias dedicadas solo a reciclar y crear productos reciclables, industrias que no dejan desperdicios sino insumos para crear otros productos también reciclables; así sólo se podría contabilizar como riqueza la producción industrial.

\section{EN EL PERÚ}

El PBI del 2007 fue de $8.99 \%$, el más alto de los últimos 14 años, lo que representó el mayor crecimiento del PBI desde 1994, año en que alcanzó $12.8 \%$. El resultado global fue incluso mayor que la expectativa del propio presidente Alan García y del Ministerio de Economía y Finanzas, quienes siempre pronosticaron que el PBI llegaría a 8.3\%.

En el Perú, la medición del PBI se sostiene en dos pilares: uno que es medido a través de encuestas, y el segundo que es calculado solamente a través de una regla de tres simple. Farid Matuk, ex presidente del Instituto Nacional de Estadística e Informática (INEI), cuestionó las cifras del $\mathrm{PBI}$, indicando que no son confiables los índices de medición, ya que solamente los sectores de agricultura, pesca, minería, manufactura, electricidad y agua son actualmente medidos a través de encuestas, y otros sectores como construcción y comercio son medidos a través de cálculos matemáticos que toman como base el año 1994.

\section{CONCLUSIONES}

1. Mientras el PBI no sea reemplazado por un nuevo indicador, la destrucción ecológica del planeta no cesará, ya que el PBI puede crecer pero nuestra casa mayor, el planeta, no.

2. En la percepción de que los recursos naturales son un regalo de la naturaleza se atribuye un "no" costo al agotamiento del recurso como resultado de la extracción.

3. Hay que valorar los efectos de la actividad humana sobre los ecosistemas, ya que si pensamos que la degradación ambiental es la contraparte de la calidad de vida, tenemos motivo suficiente para integrarla en las discusiones del crecimiento y el desarrollo.

4. Quizás, en un futuro no muy lejano, tendremos que medir la inviabilidad de las naciones por su gran escasez de agua, alimentos y energía.

5. Cuando una futura generación estudie nuestra civilización y vea que contabilizamos como desarrollo un crecimiento económico que consistía en destruir la biodiversidad, recalentar la atmósfera, derretir los glaciares, crear escasez de agua, alimentos y energía, y subir peligrosamente el nivel de los mares, propiciando el "oscurecimiento global", clasificará al PBI como el más conspicuo indicador de nuestra barbarie.

6. Cuantos más recursos destinemos a reparar el medio ambiente menos podremos dedicar a ampliar la base y calidad de activos de los pobres.

\section{BIBLIOGRAFÍA}

Aroca Sanz, Juan. (2008). Atentados contra el idioma español. Madrid, Ediciones del Prado.

De Rivero, Oswaldo. (2009). "El Indicador de la Barbarie. Malos Cálculos destruyen el Planeta”. En: El Comercio. Edición del 2009.

Giacosa, Guillermo. (2009). "Autismo Económico. Apuntes de Clases JDB". En: Perú 21. Edición del 2009.

Goodman, Peter S. (2009). “¿Es erróneo prestar tanta atención al PBI?”. En: The New York Times. Edición del sábado 3 de octubre del 2009, pág. 10. 